\title{
Human case of West Nile neuroinvasive disease in Portugal, summer 2015
}

L Zé-Zé ${ }^{12}$, P Proença ${ }^{34}$, HC Osório ${ }^{1}$, S Gomes $^{1}$, T Luz $^{1}$, P Parreira ${ }^{1}$, M Fevereiro ${ }^{5}$, MJ Alves

1. Centro de Estudos de Vectores e Doenças Infecciosas (Centre for Vectors and Infectious Diseases Research), National Health Institute Doutor Ricardo Jorge (INSA), Águas de Moura, Portugal

2. Biosystems and Integrative Sciences Institute, University of Lisbon, Faculty of Sciences, Campo Grande, Lisbon, Portugal

3. Centro Hospitalar do Algarve, Hospital de Faro, Faro, Portugal

4. Department of Biomedical Sciences and Medicine, University of Algarve, Faro, Portugal

5. Instituto Nacional de Investigação Agrária e Veterinária (INIAV; National Institute of Agrarian and Veterinary Research), Rua General Morais Sarmento, Lisbon, Portugal

Correspondence: Líbia Maria Marques Zé-Zé (libia.zeze@insa.min-saude.pt)

Zé-Zé L, Proença P, Osório HC, Gomes S, Luz T, Parreira P, Fevereiro M, Alves MJ. Human case of West Nile neuroinvasive disease in Portugal, summer 2015. Euro Surveill. 2015;20(38):pii=30024. DOI: http://dx.doi.org/10.2807/1560-7917.ES.2015.20.38.30024

Article submitted on 15 September 2015 / accepted on 24 September 2015 / published on 24 September 2015

A case of West Nile virus (WNV) infection was reported in the Algarve region, Portugal, in the first week of September 2015. WNV is known to circulate in Portugal, with occasional reports in horses and birds (2004 to 2011) and very sporadically human cases (in 2004 and in 2010). Here we present the clinical and laboratory aspects related to the first human case of West Nile neuroinvasive disease reported in Portugal.

In September 2015, a case of West Nile neuroinvasive disease was reported in a patient with neurological symptoms by molecular and serological methods at the National Health Institute (INSA), the reference laboratory for the diagnosis of flaviviruses in Portugal. Although all samples were negative for the presence of West Nile virus (WNV) RNA, positive immunofluorescence results were confirmed by virus neutralisation tests meeting the European Union case definition for WNV infections.

\section{Case description}

On 21 July 2015 a man in his 70s was assessed in the emergency room of Faro Hospital with a history of six days of high fever $\left(\geq 38.5^{\circ} \mathrm{C}\right)$, headache and altered state of consciousness with progressive prostration, drowsiness and lethargy, confusion, gait difficulty and urinary retention. A macular rash was seen on arms and thighs.

The patient, who lives in a rural area in Almancil, Algarve had frequent contact with animals (chickens, pigs, sheep and horses), had not travelled abroad in the previous year and reported that he had never been vaccinated against flaviviruses (yellow fever, tick-borne encephalitis or Japanese encephalitis virus).
The laboratory findings in the hospital showed haemoglobin $12.4 \mathrm{mg} / \mathrm{dL}$ (norm: 13-17 g/dL), leukocytes $14.8 \times 10^{9} / \mathrm{L}$ (norm: $4-10 \times 10^{9} / \mathrm{L}$ ) and C-reactive protein $40 \mathrm{mg} / \mathrm{L}$ (norm: $<5 \mathrm{mg} / \mathrm{L}$ ). Cerebrospinal fluid (CSF) showed 103 cells $/ \mathrm{mm}^{3}$ (norm: $<6$ cells $/ \mathrm{mm}^{3}$ ) with a predominance of lymphocytes, $143 \mathrm{mg} / \mathrm{dL}$ protein (norm: 15-60 mg/dL) and $58 \mathrm{mg} / \mathrm{dL}$ glucose (norm: 40-60 mg/ $\mathrm{dL})$.

At the emergency room, viral meningoencephalitis, rickettsial meningoencephalitis or bacterial meningitis diagnosis were considered and the patient was empirically treated with ceftriaxone ( $2 \mathrm{~g}, 12 / 12 \mathrm{~h}$ for 14 days) and doxycycline (100 mg, 12/12 h for 7 days). CSF sample molecular analyses were requested for neurotropic viruses (herpes simplex viruses ( 1 and 2 ), Varicella zoster virus, Epstein-Barr virus, cytomegalovirus, human herpes virus (6, 7 and 8) and enterovirus) and arboviruses (Toscana virus and WNV). Serological analysis for Borrelia burgdorferi, Coxiella burnetii, Brucella sp., Epstein-Barr virus, Hepatitis B and C viruses, humanimmunodeficiency virus (1 and 2), Mycoplasma pneumonia, Rickettsia conorii and Treponema pallidum were also requested. All results became negative except for C. burnetii IgG 200 (cut-off: 200), and serological analysis were requested for Toscana virus and WNV.

After 14 days, the patient had a good outcome and was discharged with minimal residual neurological disease, i.e. some slowing in speech and action. Thirtyfour days after the onset of symptoms he returned for further evaluation and blood tests, and neurological examination showed full recovery.

\section{Molecular and serological diagnostics}

In the National Institute of Health (INSA), a CSF sample taken on day 6 after symptoms onset was negative 
for West Nile virus (WNV) in a RT-PCR specific for WNV lineages 1 and 2 [1]. A urine sample collected on day 34 after symptom onset was also negative by real-time RT-PCR $[1,2]$. Both samples were also negative when tested by generic pan-flavivirus conventional RT-PCR [3].

A serum sample taken on day 16 after symptom onset was tested by an in-house immunofluorescence assay was positive for WNV-specific IgM with a titre of 1,024 (cut-off:16) and IgG with a titre of 2,048 (cut-off: 32 ). A second serum sample taken on day 34 after symptom onset showed a WNV-specific IgM titre of 64 and IgG titre of 4,096. Both serum samples were also subjected to immunofluorescence assays for immunoglobulins specific to other flaviviruses, such as yellow fever, tick-borne encephalitis, Dengue, Zika and Japanese encephalitis virus. All were negative for IgM and presented IgG cross-reaction. A WNV-specific IgM antibody response in CSF, a criterion for case confirmation, was not tested due to the lack of available samples after PCR diagnosis.

The serum samples from day 16 and 34 were tested by microneutralisation assay. Replicates of twofold dilutions of the inactivated test sera were incubated with 100 TCID50 of WNV (strain Egypt 101) at $37^{\circ} \mathrm{C}$ for 1 hour in 96-well microtitre plates. Vero E6 cells were added $\left(2 \times 10^{4} /\right.$ well $)$ and plates were incubated at $37^{\circ} \mathrm{C}$ under $5 \% \mathrm{CO}_{2}$. Plates were examined microscopically for cytopathic effects at 4 days post addition of cells. Standard positive (West Nile (strain Eg 101) immune mouse ascytis fluid, CDC, Atlanta) and negative sera were included in the assays. Virus used in each run of the test was back-titrated to confirm the validity of the test. Titres were assigned arithmetically as the dilution of serum giving a 50\% neutralisation endpoint. Serum neutralising antibody titres of 10 or higher were considered significant. Microneutralisation assays of both serum samples were positive to a titre of 2,560 .

\section{Background}

WNV is the most widely distributed mosquito-transmitted flavivirus in the world, and the aetiological agent of West Nile fever and West Nile neuroinvasive disease (WNND) [4]. The virus is maintained in nature in enzootic cycles involving ornithophilic mosquitoes, mainly Culex species, as primary vectors and some species of birds as primary reservoirs.

WNV transmission via blood transfusion or organ transplantation is a public health threat because WNV disease symptoms are estimated to occur in only about $20 \%$ of infected people (of those, less than 1\% may develop WNND). Most infections are asymptomatic (80\%) and asymptomatic viraemic donors can transmit the virus to immunocompromised or vulnerable recipients [5]. The acknowledgement of the risk of infected blood donations in the affected areas and the emergence of WNV in Europe in the past 10 years prompted the European Commission to release a preparedness plan for WNV and blood safety in 2012 [6].

WNV is known to circulate in Portugal with frequent detections in horses and birds [7]. INSA performs reference laboratory diagnosis of flaviviruses in Portugal and previously identified a probable human case in 2010 [8], triggering a WNV survey in horses living in the same area. The survey identified two WNV-positive horses [7]. The first confirmed human cases were diagnosed in two tourists in Ireland after a trip to Algarve in 2004 [9]; they had acquired the infection in the proximity of the human case identified this year.

\section{Public health measures}

The patient reported here represents the first serumpositive case to date in Portugal. After the communication of the clinical suspicion of a probable case of WNND, clinical, epidemiological and serological surveillance was implemented by the local health authorities in order to assess the possible presence of WNV in susceptible species in the area [10].

Although the detection of viral RNA is an unambiguous prove of WNV infection, it is known to be challenging in patients with symptomatic infections because viraemia can be low or absent at the time of symptom onset [2]. The negative PCR results in CSF and urine were not unexpected seeing as the samples were collected after the beginning of symptoms. The positive immunofluorescence results were confirmed by virus neutralisation test to ascertain the case confirmation according to the European Union case definition for WNV infections [11].

On 3 September, the General Directorate of Veterinary (DGAV; Direcção Geral de Alimentação e Veterinária, Ministério da Agricultura e do Mar) reported three new outbreaks in horses in Loulé, Algarve municipality, and so far, four of 82 horses analysed were positive for WNV infection [12].

The Algarve region possesses a large a coastal area characterised by marshlands, salt marshes, small islands, dunes and beaches. Several wetlands and bird sanctuaries are present. Fishery, aquaculture and salt extraction are important human activities, as is tourism particularly in summer. A nationwide vector surveillance programme (REVIVE) has covered the Algarve region since 2008 [13].

\section{Conclusion}

Veterinary, human and vector surveillance was initiated in the Algarve municipality after the laboratory report of the WNND human case and is still ongoing. This case highlights the essential role of laboratory diagnostics for early detection and implementation of control measures in vector-borne diseases outbreaks.

Conflict of interest

None declared. 
LZZ: manuscript preparation and molecular diagnosis at INSA; PP: clinical data and laboratory findings in Algarve; LZZ, MJA, SG, TL, PP: serological diagnosis at INSA; MJA, MF: virus neutralisation diagnosis; MJA: laboratory coordination at INSA. All authors collaborated in the work and participated in the final revision of the manuscript.

\section{References}

1. BarrosSC, RamosF, Zé-ZéL, AlvesMJ, FagulhaT, DuarteM, et al. Simultaneous detection of West Nile and Japanese encephalitis virus RNA by duplex TaqMan RT-PCR. J Virol Methods.

2013;193(2):554-7. DOI: 10.1016/j.jviromet.2013.07.025 PMID: 23892127

2. BarzonL, PacentiM, FranchinE, PagniS, MartelloT, CattaiM, et al. Excretion of West Nile virus in urine during acute infection. J Infect Dis. 2013;208(7):1086-92. DOI: 10.1093/infdis/jit290 PMID: 23821721

3. BrieseT, JiaXY, HuangC, GradyLJ, LipkinWI. Identification of a Kunjin/West Nile-like flavivirus in brains of patients with New York encephalitis.Lancet. 1999;354(9186):1261-2. DOI: 10.1016/ S0140-6736(99)04576-6 PMID: 10520637

4. ReiterP. West Nile virus in Europe: understanding the present to gauge the future.Euro Surveill. 2010;15(10):19508.PMID: 20403311

5. HubálekZ. European experience with the West Nile virus ecology and epidemiology: could it be relevant for the New World?Viral Immunol. 2000;13(4):415-26. DOI: 10.1089/ vim.2000.13.415 PMID: 11192288

6. European Commission. West Nile virus and blood safety. Introduction to a preparedness plan in Europe. Based on the EU Satellite Meeting of the Working Group on Blood Safety and WNV, Thessaloniki, 25-26 January 2011 and on the teleconference, 18 January 2012. Final working document 2012 V.2.1. Prepared by: Greece, Italy, Romania and France. Brussels: EC: 2012. Available from: http://ec.europa.eu/ health/blood_tissues_organs/docs/wnv_preparedness_ plan_2012.pdf

7. Barros SC, Ramos F, Fagulha T, Duarte M, Henriques M, Luís $\mathrm{T}$, et al. Serologic evidence of West Nile virus circulation in Portugal. Vet Microbiol. 2011;152: 407-10. http://doi:DOI: 10.1016/j.vetmic.2011.05.013

8. Alves MJ, Poças JMD, Osório HC, Amaro F, Zé-Zé L. West Nile virus (Flavivirus) infection in Portugal. Considerations about a clinical case with febrile syndrome and rash. Revista Portuguesa de Doenças Infecciosas. 2012;8(1):46-51. Available from: http://repositorio.insa.pt/handle/10400.18/989

9. Connell, McKeownP, GarveyP, CotterP, ConwayA, O'FlanaganD, et al. Two linked cases of West Nile virus (WNV) acquired by Irish tourists in the Algarve, Portugal. Euro Surveill. 2004;8(32):2517. Available from: http://www.eurosurveillance. org/ViewArticle.aspx?Articleld $=2517$

10. Nota sobre o Vírus do Nilo Ocidental. [Note on the West Nile Virus]. Lisbon: Directorate-General of Health (DGS); 2015. Portuguese. Available from: https://www.dgs.pt/em-destaque/ nota-sobre-o-virus-do-nilo-ocidental.aspx

11. European Commission. Commission implementing decision of 8 August 2012 amending Decision 2002/253/EC laying down case definitions for reporting communicable diseases to the Community network under Decision No 2119/98/EC of the European Parliament and of the Council. Official Journal of the European Union. Luxembourg: Publications Office of the European Union. 27.9.2012:L 262. Available from: http://eurlex.europa.eu/LexUriServ/LexUriServ.do?uri=0J:L:2012:262:00 01:0057:EN:PDF

12. Information received on 03/09/2015 from Prof. Dr. Álvaro Mendonça, Director General, Direcção Geral de Alimentação e Veterinária, Ministério da Agricultura E do Mar, Lisboa, Portugal. Paris: World Organisation for Animal Health (OIE); 3.9.2015. Available from: http://www.oie.int/wahis_2/public/ wahid.php/Reviewreport/Review?page_refer=MapFullEventRep ort\&reportid $=18585$

13. OsórioHC, Zé-ZéL, AmaroF, AlvesMJ. Mosquito surveillance for prevention and control of emerging mosquito-borne diseases in Portugal - 2008-2014. Int J Environ Res Public Health. 2014;11(11):11583-96. http://www.mdpi.com/16604601/11/11/11583DOI: 10.3390/ijerph111111583 PMID: 25396768 